\title{
REJUVENATION OF NICKEL-BASED SUPERALLOYS GTD444(DS) and RENÉ N5(SX)
}

\author{
L. H. Rettberg ${ }^{1}$, M. Tsunekane ${ }^{2}$, T. M. Pollock ${ }^{1}$ \\ ${ }^{1}$ University of California, Santa Barbara, Materials Dept.; Santa Barbara, CA 93106-5050, USA \\ ${ }^{2}$ Brown University, School of Engineering; Providence, RI, 02192, USA
}

Keywords: Rejuvenation, Creep, Rafting, Creep Cavitation, Recrystallization, GTD444, René N5

\begin{abstract}
Damage accumulation during creep has been examined for two nickel-based superalloys; single crystal René N5 and directionally solidified GTD444. Creep was performed at $980^{\circ} \mathrm{C} / 172 \mathrm{MPa}$ and $980^{\circ} \mathrm{C} / 206 \mathrm{MPa}$ for GTD444 and René N5, respectively. Specimens were crept until failure or interrupted at $2 \%$ or $5 \%$ strain. Creep cavitation was minimal until after $5 \%$ strain for both René N5(SX) and GTD444. Based on this result, hot isostatic pressing was deemed unnecessary to rejuvenate creep properties. Rafting was observed at $2 \%$ strain and continued until failure. Electron backscattered diffraction, used to quantify the local misorientation around microstructural features, showed enhanced dislocation activity around carbides. Indications of carbideinitiated recrystallization were observed at $5 \%$ creep strain during creep testing. At both $2 \%$ and $5 \%$ strain, solution heat treatment at $1293^{\circ} \mathrm{C}$ for $20 \mathrm{~min}$ caused dissolution of carbides and refined the $\gamma^{\prime}$ rafts to sub-micron sized spherical precipitates.
\end{abstract}

\section{Introduction}

Ni-based superalloys have been used for decades in combustion turbines due to their excellent combination of high-temperature strength, toughness, corrosion, and oxidation resistance. Turbine components are subjected to a complex combination of stresses at high temperatures leading to significant material degradation over time. Such degradation during service mandates the periodic replacement of expensive components. The high cost of replacement components has encouraged the development of rejuvenation (restoration) procedures to extend the service lives of components. The purpose of this work is to investigate microstructural issues that limit the rejuvenation of creep properties of Directionally Solidified (DS) GTD444 and Single Crystal (SX) René N5 following creep deformation. Heat treatments that recover creep properties have also been investigated.

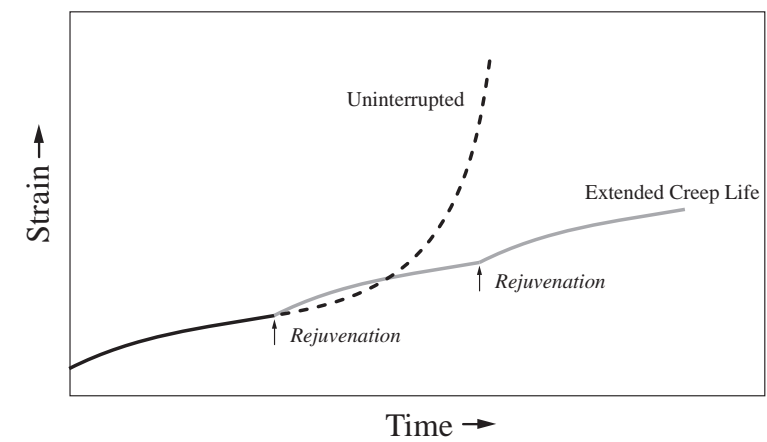

Figure 1: Schematic showing a typical uninterrupted creep curve tested to failure and an idealized creep curve as a result of successful rejuvenation.

\section{Background}

By periodically conducting a rejuvenation procedure involving recovery heat treatment at low creep strains, it is expected that the creep life of GTD444(DS) and René N5(SX) will be extended (Fig. 1). Rejuvenation of gas turbine components has been previously explored for a number of materials, typically by determining the impact of reheat treatment on creep life recovery [1-4]. Simple creep experiments are used to induce damage due to the difficultly and expense of replicating service conditions. Commonly observed internal degradation processes that occur during creep include: precipitate coarsening or rafting, changes in carbide size or morphology, cavity or void formation, and the generation of topologically close packed (TCP) phases [5]. After inducing damage, rejuvenation heat treatments are performed above the $\gamma^{\prime}$ solvus temperature to hypothetically revert the microstructure to pre-crept condition and recover creep life. However, due to experimental scatter, the success of a rejuvenation treatment is frequently inconclusive. Dennison et al. suggest that unsuccessful rejuvenation treatments are a result of incomplete recovery of the dominant tertiary creep mechanism [1]. In essence, heat treatments must be individually designed for each alloy. 
For example, when creep behavior is controlled by microstructure, complex heat treatments involving solutioning and aging must be performed. However, rejuvenation following tertiary creep driven by creep cavitation rather than microstructure evolution would additionally require hot isostatic pressing (HIP) for recovery of properties. Thus, the damage mechanisms that occur during tertiary creep must be characterized in detail, particularly in directionally solidified (DS) or single crystal (SX) alloys, where the tertiary creep regime often accounts for a large fraction of the total creep life.

Previous research on rejuvenation has primarily focused on polycrystalline Ni-based alloys, mainly Nimonic and Inconel alloys. Hart and Gayter found that successful rejuvenation of Nimonic 90 depended on the creep conditions, namely the stress and temperature [2]. At high temperatures and low stresses $\left(807^{\circ} \mathrm{C}, 108 \mathrm{MPa}\right)$ voids grew as a result of stress-directed vacancy flow and could be sintered via heat treatment, extending creep life. However, at lower temperatures and higher stresses $\left(650^{\circ} \mathrm{C}\right.$, $597 \mathrm{MPa}$ ) cracks were initiated by grain boundary sliding and could not be repaired by heat treatment. Moderate success in restoring creep properties was reported by Maccagno, et al., on service-exposed IN 713C turbine blades [4]. The most successful rejuvenation treatment consisted of a heat treatment and HIP, with creep properties being restored to 50 to $75 \%$ of the original levels. The size and distribution of $\gamma^{\prime}$ were similar to the pre-crept blades, due to HIP at $1200^{\circ} \mathrm{C}$ (i.e. above the $\gamma^{\prime}$ solvus temperature) and subsequent aging. Lamberigts, et al., performed rejuvenation procedures on specimens machined from directionally solidified Mar-M-200 + Hf turbine blades [3]. Service damage was simulated by performing stress-rupture tests. HIP at a temperature near the $\gamma^{\prime}$ solvus $\left(1230^{\circ} \mathrm{C}\right)$, followed by full solutioning and aging was used to completely heal $\gamma^{\prime}$ rafting and incipient melting. The performance of rejuvenated specimens fell within the experimental scatter of pre-crept specimens.

A side effect of solutioning near or above $\gamma^{\prime}$ solvus is the highly undesirable formation of recrystallized grains. With little to no strength, recrystallized grains significantly compromise component performance, specifically fatigue life and stress rupture strength [6]. Recrystallization in SX and DS nickelbased superalloys has been explored in a few papers, where hardness indentations, shot peening, or cold rolling were typically used to induce damage, causing recrystallization during subsequent heat treatments
[7-11]. Bürgel, et al. investigated recrystallization in four single crystal nickel-based superalloys: CMSX11B, PWA 1483, SRR99, and CMSX-6 [7]. Damage was induced by cold working and after solutioning above the $\gamma^{\prime}$ solvus temperature, the critical degree of cold work for recrystallization was less than $2 \%$ for all alloys. Carbides had a minimal effect on the recrystallization kinetics as recrystallized grains nucleated at the surface in all cases. More related to the present work, Cox, et al., conducted tensile tests on CMSX-4 to known values of plastic strain at room and elevated temperatures followed by annealing at various temperatures for $6 \mathrm{~h}$ [8]. Annealing at a temperature of $1295^{\circ} \mathrm{C}$ caused recrystallization in tensile specimens tested to a plastic strain of between 3 and $4 \%$. At an annealing temperature above the $\gamma^{\prime}$ solvus the critical strain for recrystallization decreased to between 1 and $2 \%$ strain, showing the pinning effect of the $\gamma^{\prime}$ precipitates. Closely spaced second phase particles will pin grain boundaries, suppressing recrystallization. The critical annealing temperature to cause recrystallization decreased with increasing tensile testing temperature for CMSX-4. This was believed to be due to the $\gamma^{\prime}$ precipitates behaving as undeformable particles at high temperatures, increasing stored energy and hence the driving force for recrystallization. The effect of subsequent reheating and dissolving of the $\gamma^{\prime}$ was not investigated for specimens tested at elevated temperature.

The work presented here uses high temperature/low stress creep to induce damage in GTD444(DS) and René N5(SX) alloys. The character of the creep damage that accumulates in both alloys has been investigated. An initial investigation into the effectiveness of solution heat treatment in dissolving the $\gamma^{\prime}$ phase while avoiding recrystallization is also reported. The implications of the experimental observations for rejuvenation cycle development are then discussed.

\section{Experimental Procedure}

Creep specimens machined along the [001] crystal direction from GTD444(DS) and René N5(SX) liquid metal cooled (LMC) plates were crept to failure and also interrupted at $2 \%$ and $5 \%$ creep strain. LMC plates had dimensions of $13 \times 24 \times 1.5 \mathrm{~cm}$ and were solutioned and aged with standard commercial cycles. Special care was taken to minimize surface damage in the creep specimens due to machining by using low stress grinding. Nominal alloy compositions are listed in Table I. 
Table I: Composition, in weight percent, of the DS and SX gas turbine alloys investigated in this study.

\begin{tabular}{lcccccccccccc}
\hline & $\mathrm{Cr}$ & $\mathrm{Co}$ & $\mathrm{Mo}$ & $\mathrm{W}$ & $\mathrm{Ta}$ & $\mathrm{Nb}$ & $\mathrm{Al}$ & $\mathrm{Ti}$ & $\mathrm{Hf}$ & $\mathrm{Re}$ & $\mathrm{Ni}$ & Ref. \\
\cline { 2 - 11 } GTD444 (DS) & 9.7 & 8 & 1.5 & 6 & 4.7 & 0.5 & 4.2 & 3.5 & 0.15 & - & Bal. & {$[12]$} \\
René N5(SX) & 7 & 7.5 & 1.5 & 5 & 6.5 & - & 6.2 & - & 0.15 & 3 & Bal. & {$[13,14]$} \\
\hline
\end{tabular}

Creep tests were performed under constant load in air at the following conditions: $980^{\circ} \mathrm{C} / 172 \mathrm{MPa}$ and $980^{\circ} \mathrm{C} / 206 \mathrm{MPa}$ for GTD444 and René N5, respectively.

The microstructure was examined for both alloys after testing to determine the onset of recrystallization, extent of rafting, formation of cavities or voids, changes in carbide morphology, and precipitation of brittle intermetallic phases. The results were compared to the pre-crept microstructure. Metallographic preparation of pre-crept and crept specimens involved mounting sections parallel and transverse to the stress axis in Bakelite, followed by standard grinding and polishing with a final polish of 0.05 $\mu m$ alumina. Specimens were ultrasonically cleaned after each polishing step in distilled water. Two etchants were used to inspect the microstructure: $40 \%$ hydrochloric acid, $40 \%$ ethylene glycol and $20 \%$ nitric acid for macroetching GTD444(DS); $33 \%$ distilled water, $33 \%$ acetic acid, 33\% nitric acid and $1 \%$ hydrofluoric acid for microetching of GTD444(DS) and René N5(SX).

Electron backscatter diffraction (EBSD) was performed on samples from interrupted creep experiments to determine the Kernal average misorientation (KAM) and to investigate the presence or absence of dynamic recrystallization. The KAM is defined for a given point (pixel) as the average misorientation of that point with respect to all of its neighbors [15]. EBSD data were acquired using a FEI 235 field emission gun (FEG) SEM with a sample tilt of $70^{\circ}$ and a working distance of $18 \mathrm{~mm}$. The SEM was operated at $20 \mathrm{kV}$ with a $0.10 \mu \mathrm{m}$ step size.

To investigate the onset of any recrystallization processes, exploratory heat treatment procedures on René N5(SX) involved solution treatment at $1293^{\circ} \mathrm{C}$ for $20 \mathrm{~min}$, followed by water quenching were conducted. Sections were cut from crept specimens via electrical discharge machining (EDM) and were encapsulated in a quartz tube with an argon atmosphere. A tube furnace was used with a heating rate of $316^{\circ} \mathrm{C} / \mathrm{h}$.

\section{Results \& Discussion}

The pre-crept microstructure of both GTD444(DS) and René N5(SX) is shown in Fig. 2. Both alloys exhibited two distinct distributions in the size and shape of the $\gamma^{\prime}$ phase, due to solidification induced segregation. For both alloys the interdendritic regions contained larger $\gamma^{\prime}$ precipitates when compared to the $\gamma^{\prime}$ precipitates in the dendrite cores. Carbides were also present in both alloys, while only GTD444(DS) contained $\gamma / \gamma^{\prime}$ eutectic pools. Neither alloy had optimal $\gamma^{\prime}$ shape to maximize creep life, with semi-spherical and semi-cuboidal shaped $\gamma^{\prime}$ present for GTD444(DS) and René N5(SX), respectively. The pre-crept microstructure for GTD444 was comparable to that reported in recent literature $[16]$.

Creep tests performed at $980^{\circ} \mathrm{C} / 172 \mathrm{MPa}$ and $980^{\circ} \mathrm{C} / 206 \mathrm{MPa}$ for GTD444 and René N5 resulted in creep lives of $250 \mathrm{~h}$ and $200 \mathrm{~h}$, respectively, Fig. 3. Experimental scatter was observed between the five creep tests performed for each alloy and is most likely due to variations in porosity, carbide structure, and crystal misorientation with respect to the [001] direction. Examination of the post-test microstructure indicated that no significant creep cavitation occured at $2 \%$ or $5 \%$ creep strain in either alloy, Fig. 4. However, post-failure specimens exhibited creep cavitation in the interdendritic regions near carbides close to the fracture surface, indicating that beyond $5 \%$ creep strain, cavities formed, Fig. 4. Significant necking was also observed near the fracture surface, Fig. 4. Cavities nucleated and grew near carbides as hard particles act as stress concentrators, resulting in enhanced dislocation activity in surrounding areas and crack formation $[17,18]$. The growth and coalescence of creep cavities was the ultimate cause of failure. Based on these results, HIP to sinter internal defects (cavities) was deemed unnecessary to rejuvenate creep properties up to $5 \%$ strain. Minor carbide dissolution occurred during testing and TCP phases were not observed.

Rafting occurred in both alloys perpendicular to the stress axis due to a negative lattice misfit [19]. Fig. 5 shows the progression of rafting from the 


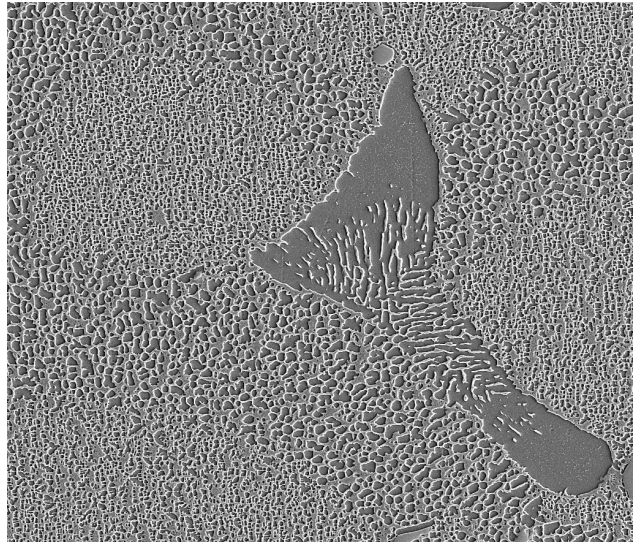

(a)

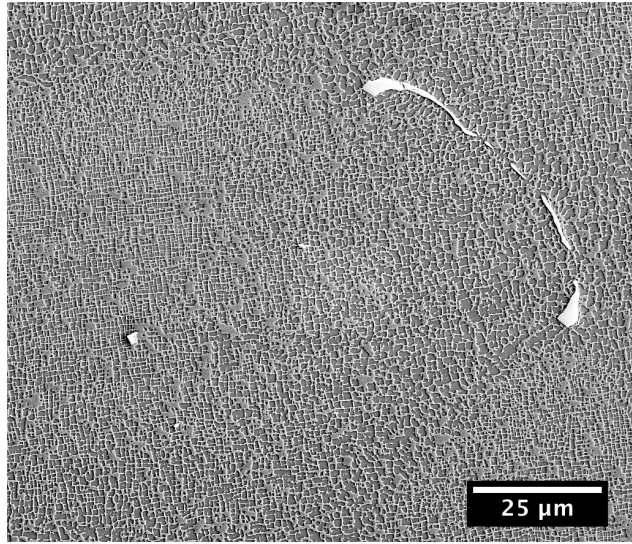

(b)

Figure 2: Secondary electron (SE) images showing the original microstructure for GTD444(DS) (a), René N5(SX) (b). The dark phase is $\gamma^{\prime}$, lighter regions are the $\gamma$ phase, and white particles are carbides. The continuous dark grey region in (a) is a $\gamma / \gamma^{\prime}$ eutectic pool. The scale is the same for both images and both samples were etched. GTD444(DS) was etched using a solution of $40 \%$ hydrochloric acid, $40 \%$ ethylene glycol and $20 \%$ nitric acid. René N5(SX) was etched using a solution of $33 \%$ distilled water, $33 \%$ acetic acid, $33 \%$ nitric acid and $1 \%$ hydrofluoric acid.

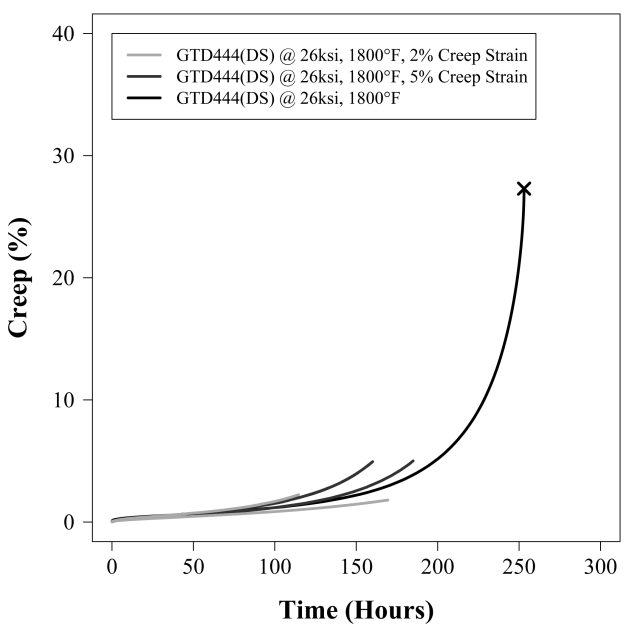

(a)

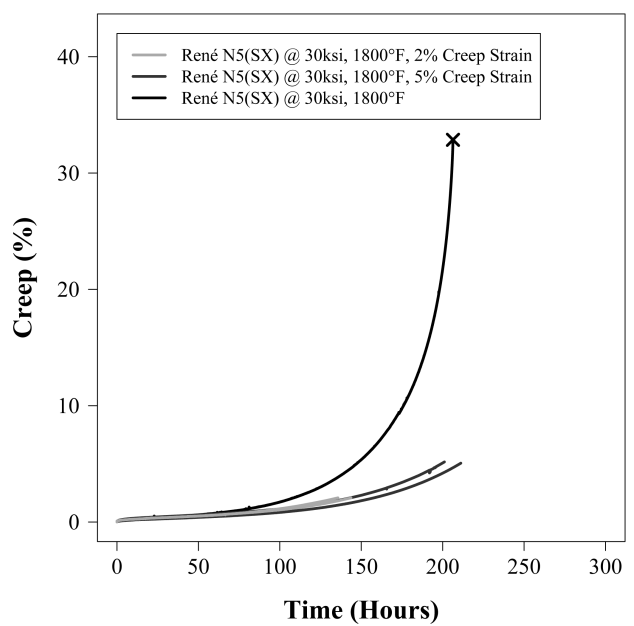

(b)

Figure 3: Creep curves for GTD444(DS) (a) and René N5(SX) (b) with time in hours on the horizontal axis and accumulated percent creep strain on the vertical axis.

pre-crept microstructure, $2 \%$ creep strain, $5 \%$ creep strain, and post-failure. Shearing of the $\gamma^{\prime}$ rafts was observed in the post-failure microstructure, see Figs. $5 \mathrm{~d}$ and $5 \mathrm{~h}$, for both alloys and may have prevented complete inversion of the microstructure.

Since carbide particles are harder than the surrounding $\gamma / \gamma^{\prime}$ material, EBSD scans for René N5(SX) were performed near carbides to further investigate their impact on dislocation activity via measurement of the local misorientation. Local crystal rotation (misorientation) has been previously linked quantitatively to local excess dislocation density [20-22]. Scans were collected from specimens interrupted at $2 \%$ and $5 \%$ creep strain. At $2 \%$ creep strain, local misorientation, as determined by examining kernel average misorientation (KAM) maps, was minimal. However, "hot spots" of $3^{\circ}$ of misorientation were observed near carbides, similar to results reported by Karamched, et al. [23]. Significantly more local 


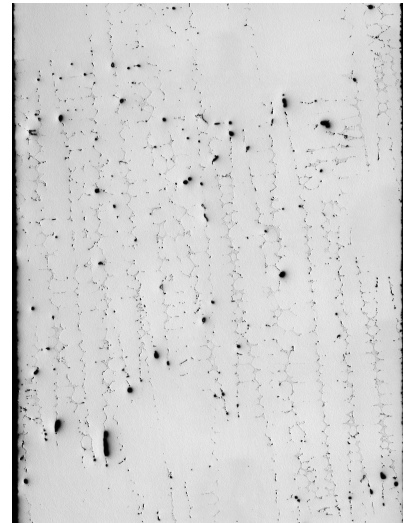

(a)

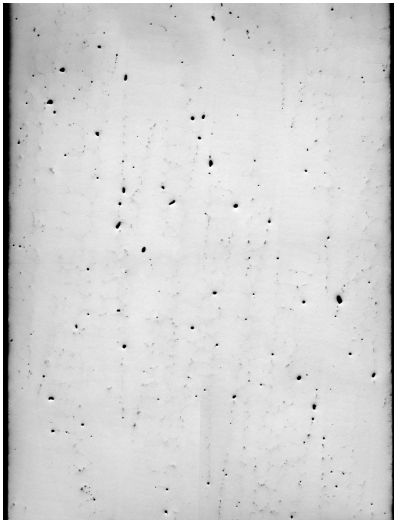

(b)

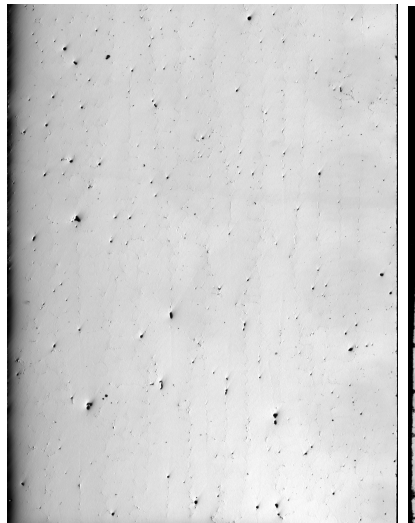

(c)

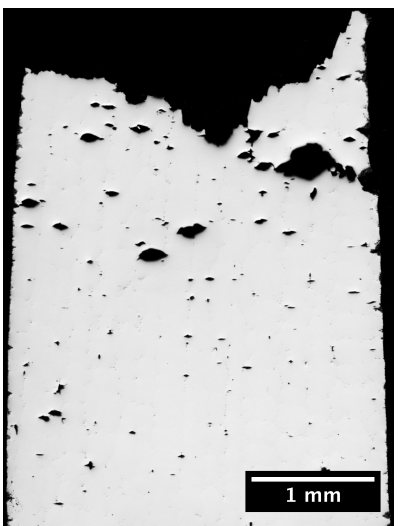

(d)

Figure 4: Montage of optical micrographs showing the initial porosity and creep cavitation in René N5(SX) as a function of strain. The microstructure was examined in the pre-crept (a), $2 \%$ strain (b), $5 \%$ strain (c), and postfailure (d) conditions. The amount of porosity and creep cavitation for GTD444 was similar to René N5(SX) at all conditions. The scale is the same for all images and samples were imaged in the as polished condition. Stress axis is along the long direction of the page.

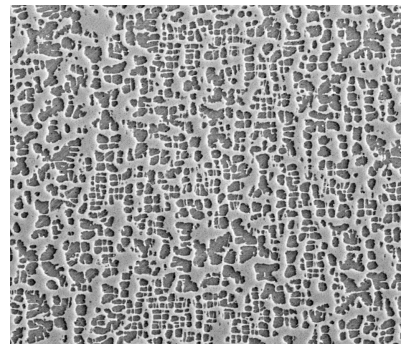

(a)

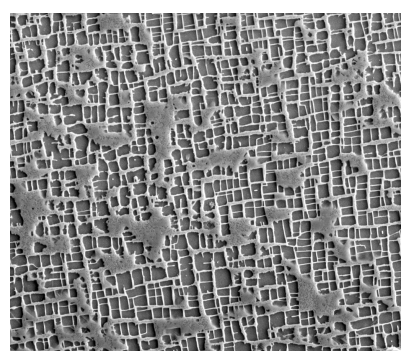

(e)

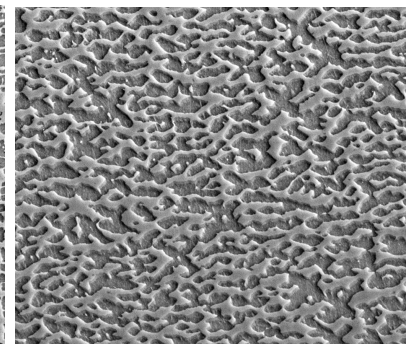

(b)

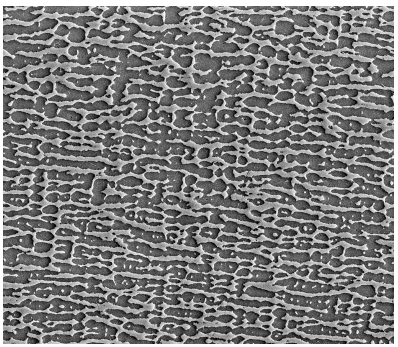

(f)

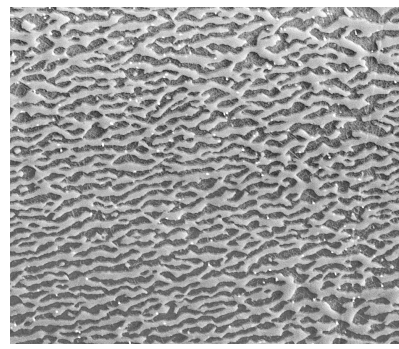

(c)

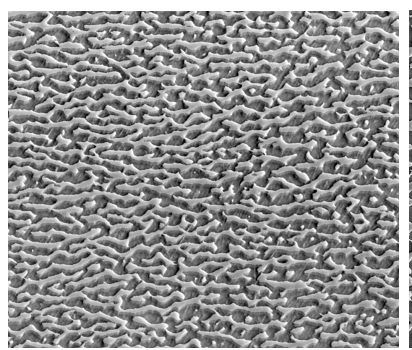

(g)

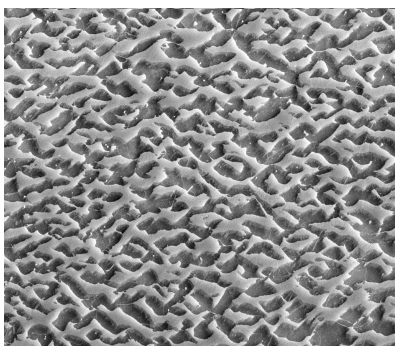

(d)

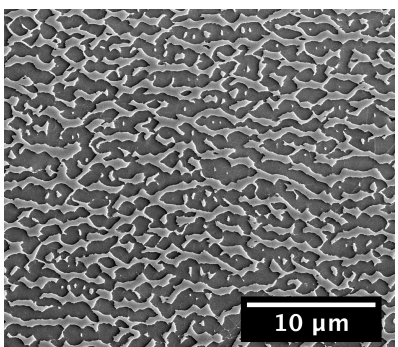

(h)

Figure 5: Montage of SE micrographs showing the progression of rafting as a function of accumulated creep strain for GTD444 pre-crept (a), 2\% creep strain (b), 5\% creep strain (c), and post-failure (d), and similarly for René N5(SX) (e)-(h). Stress axis is along the long direction of the page. The scale is the same for all images and samples were etched. The etchant used for both alloys consisted of $33 \%$ distilled water, $33 \%$ acetic acid, $33 \%$ nitric acid and $1 \%$ hydrofluoric acid. 


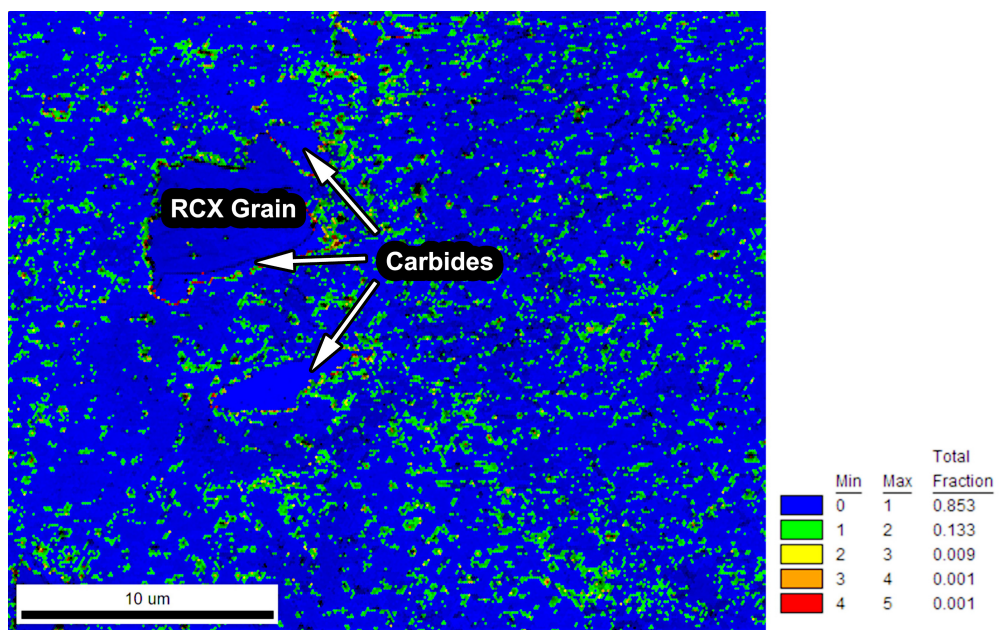

(a)

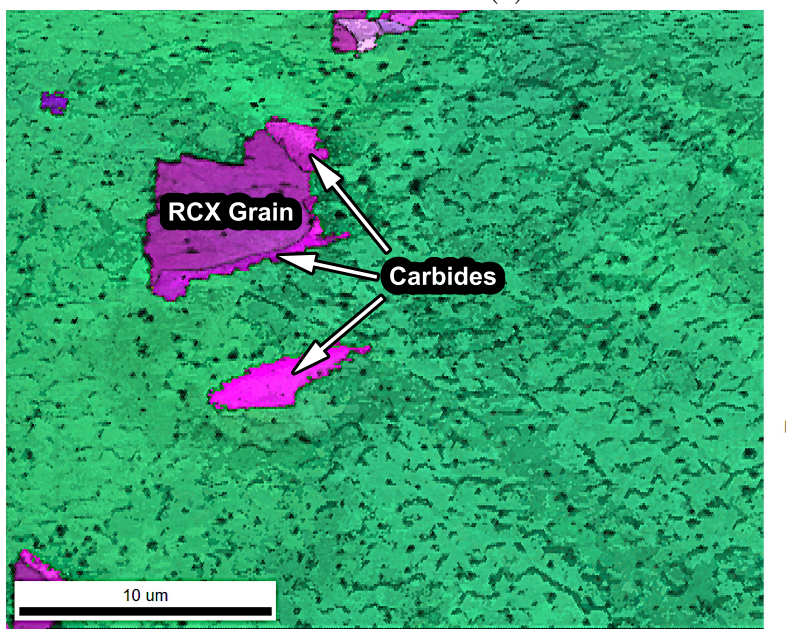

Nickel

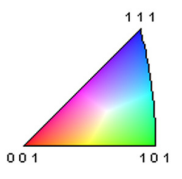

(b)

Figure 6: Results of electron backscatter diffraction, kernal average misorientation (a) and inverse pole figure (b) maps for René N5(SX) after an interrupted creep test to 5\% strain. Blue pixels in (a) correspond to low misorientation and red pixels indicate high misorientation. The dark purple grain in (b) is a recrystallized grain.

misorientation was observed after $5 \%$ creep strain, with a high degree $\left(4-5^{\circ}\right)$ of misorientation near carbides, Fig. 6. In only one sample examined, recrystallization, as indicated by the inverse pole figure (IPF) map, occurred after $5 \%$ creep strain, Fig. 6b. Recrystallization occurred in the sample during creep testing at $980^{\circ} \mathrm{C} / 206 \mathrm{MPa}$ and was not associated with a subsequent solution treatment. Only one recrystallized (RCX) grain was observed and that grain nucleated in an area of high misorientation near a cluster of carbides. Recrystallization is undesirable in GTD444(DS) and René N5(SX) as RCX grains have little to no strength and may significantly reduce fatigue and creep life. Due to the difficultly in removing RCX grains, this suggests that full recovery of materials properties would only be possible with $<5 \%$ creep strain accumulation.

Solution heat treatment of René N5(SX) was performed at $1293^{\circ} \mathrm{C}$ for 20 minutes. The solution treatment caused significant dissolution of carbides and led to a refinement in the $\gamma^{\prime}$ precipitate diameter at $2 \%$ and $5 \%$ creep strain, Fig. 7. The dissolution of carbides should have a negligible effect on mechanical properties of René N5(SX) and the $\gamma^{\prime}$ precipitates were, most likely, completely dissolved at temperature and then precipitated during cooling. Additional recrystallization did occur for the $5 \%$ creep strain sample and no RCX grains were observed in the $2 \%$ creep strain sample, but it should 


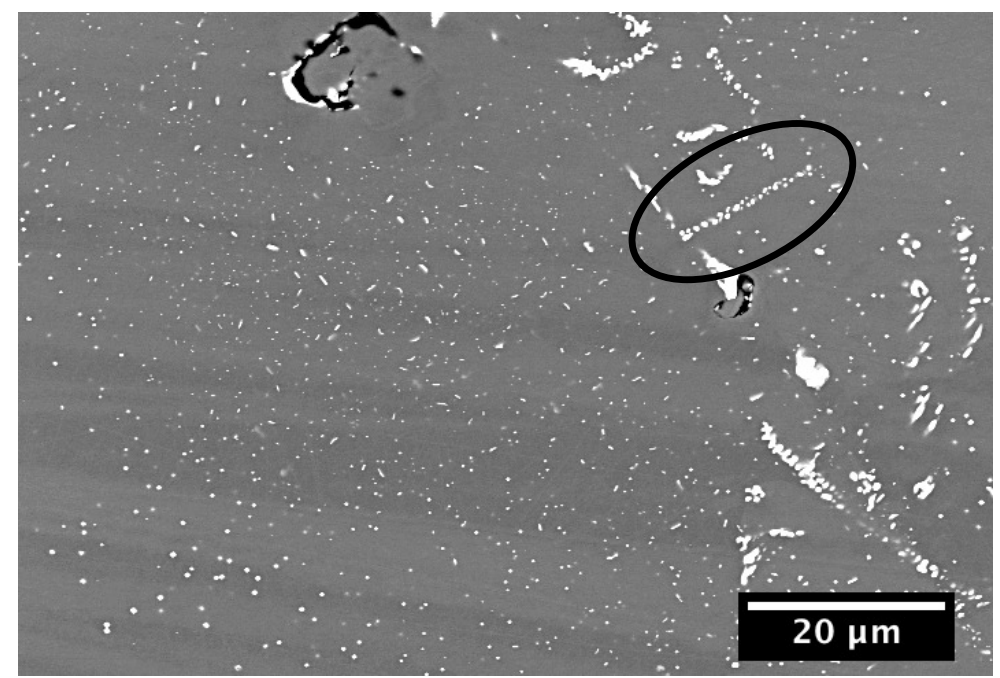

(a)

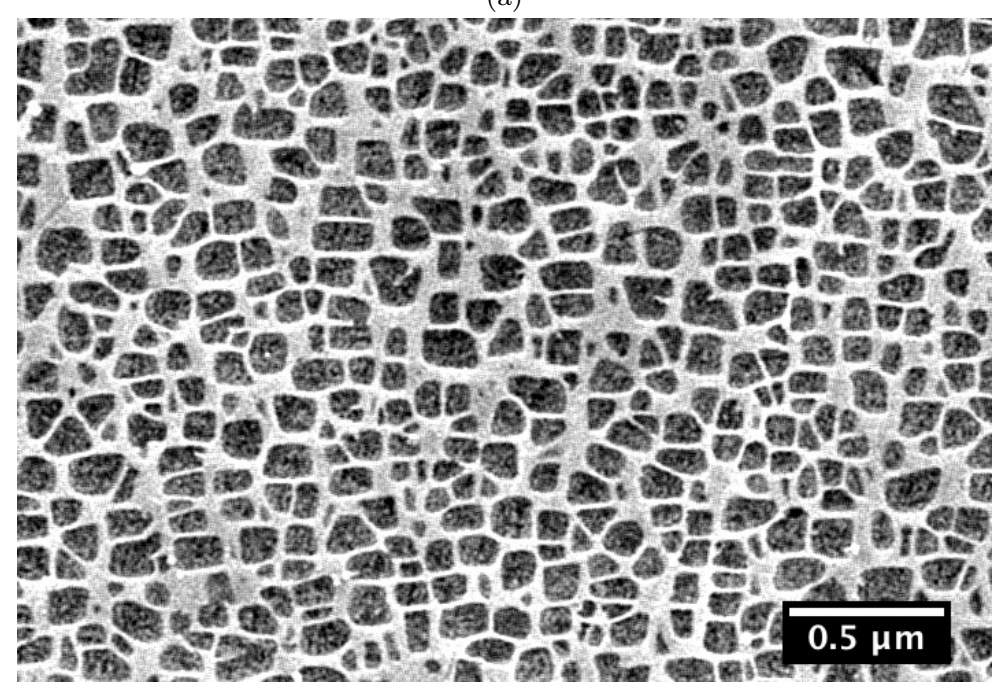

(b)

Figure 7: Low magnification (a) and high magnification (b) backscatter electron micrographs of René N5(SX) with $5 \%$ creep strain following a solution treatment at $1293^{\circ} \mathrm{C}$ for $20 \mathrm{~min}$. A dissolved carbide has been circled for clarity. The etchant used consisted of $33 \%$ distilled water, $33 \%$ acetic acid, $33 \%$ nitric acid and $1 \%$ hydrofluoric acid.

be noted that the initial solution treatment was for a conservative 20 minutes.

In summary, interrupted creep tests at both $2 \%$ and $5 \%$ strain had a rafted microstructure, with minimal creep cavitation. Creep testing to $5 \%$ strain significantly increased the stored energy in the sample, especially near carbides, leading to the nucleation and growth of a RCX grain. Initial solution heat treatments of René N5(SX) refined the $\gamma^{\prime}$ precipitate size by fully dissolving the $\gamma^{\prime}$ phase into solution. Further recrystallization did occur during solutioning for the $5 \%$ creep strain sample. Additional heat treatments with longer exposure times and lower temperatures will be conducted.

\section{Conclusions}

1. Initial microstructure of GTD444(DS) and René N5(SX) contained $\gamma^{\prime}$ and carbides, while only GTD444(DS) had $\gamma / \gamma^{\prime}$ eutectic pools.

2. Minimal creep cavitation was observed in GTD444(DS) and René N5(SX) up to 5\% creep strain, indicating that HIPing will not be required. 
3. Rafting was present at $2 \%$ creep strain in both alloys and continued until failure but was not significant enough to invert the microstructure.

4. EBSD indicated increased dislocation activity at $2 \%$ and $5 \%$ creep strain around carbides when compared to the matrix for René N5(SX). One recrystallized grain was detected at $5 \%$ creep strain and nucleated during creep testing.

5. A preliminary rejuvenation heat treatment, involving only a solution treatment cycle, has been conducted for René N5(SX) and caused significant dissolution of carbides and refinement of the $\gamma^{\prime}$ precipitates at both $2 \%$ and 5\% creep strain. The solutioning time was long enough to cause additional recrystallization at $5 \%$ creep strain.

\section{Acknowledgments}

The authors would like to thank GE Energy, specifically Steve Balsone, Andrew Elliott, and Jon Schaeffer, for providing financial support and technical guidance. A special thanks is made to fellow group members and Chris Torbet, for additional technical support.

\section{References}

1. J. P. Dennison, I. C. Elliot, and B. Wilshire, American Society for Metals. Proc. 4th Int. Symp. on Superalloys, Materials Park, OH, 1980.

2. R. V. Hart and H. Gayter. Recovery of Mechanical Properties in Nickel Alloys by Re-HeatTreatment. Journal of the Institute of Metals, 96:338-344, 1968.

3. M Lamberigts and P Vierset. Structural Damage and Rejuvenation of Used Turbine Blades. In High temperature alloys for gas turbines and other applications, pages 821-830, 1986.

4. T. M. Maccagno, A. K. Koul, J. P. Immarigeon, L. Cutler, R. Allem, and G. L'espérance. Microstructure, creep properties, and rejuvenation of service-exposed alloy $713 \mathrm{C}$ turbine blades. Metallurgical Transactions A, 21(12):3115-3125, December 1990.

5. A James. Review of rejuvenation process for nickel base superalloys. Materials Science and Technology, 17:481-486, 2001.
6. D. Goldschimdt, U. Paul, and P. R. Sahm. In Superalloys 1992, pages 155-164. Warrendale, PA, TMS.

7. R. Bürgel, P. D. Portella, and J. Preuhs. Recrystallization in Single Crystals of Nickel Base Superalloys. In Superalloys 2000, pages 229-238, 2000 .

8. D. C. Cox, B. Roebuck, C.M.F. Rae, and R. C. Reed. Recrystallisation of single crystal superalloy CMSX-4. Materials Science and Technology, 19:440-446, 2003.

9. L. Wang, G. Xie, J. Zhange, and L. H. Lou. On the role of carbides during the recrystallization of a directionally solidified nickel-base superalloy. Acta Materialia, 55:457-460, 2006.

10. C. Zambaldi, F. Roters, D. Raabe, and U. Glatzel. Modeling and experiments on the indentation deformation and recrystallization of a single-crystal nickel-base superalloys. Materials Science and Engineering: A, pages 433-440, 2007.

11. B. Zhang, C. H. Tao, X. Lu, C. K. Liu, C. Y. $\mathrm{Hu}$, and M. Y. Bai. Recrystallization of Single Crystal Nickel-Based Superalloy. Journal of Iron and Steel Research, 16:75-79, 2009.

12. G. K. Bouse, M. F. Henry, and J. C. Schaeffer. US Patent 5,154,884 Nickel Base Superalloys and Turbine Components Fabricated Therefrom, 2005.

13. E. W. Ross, C. S. Wukusick, and W. T. King. US Patent 5,399,313 Nickel-Based Superalloys for Producing Single Crystal Articles Having Improved Tolerance to Low Angle Grain Boundaries, 1995.

14. C. S. Wukusick and L. Buchakjian Jr. UK Patent Appl. GE2235697 Improved Property Balanced Nickel-base Superalloys for Producing Single Crystal Articles - René N5, 1991.

15. S. I. Wright, D. P. Field, and D. J. Dingley. Electron Backscatter Diffraction in Materials Science. Kluwer Academic, 2000, chp. 13.

16. G. Bouse, J. Schaeffer, and M. Henry. Optimizing SC René N4 Alloy for DS Aft-Stage Bucket Applications In Industrial Gas Turbines. In Superalloys 2008, pages 99-108. TMS (The Minerals, Metals \& Materials Society), 2008. 
17. Y. H. Kong, Q. Z. Chen, and D. M. Knowles. Effects of minor additions on microstructure and creep performance of RR2086 SX superalloys. Journal of Materials Science, 39:6993-7001, 2004.

18. Wesley D. Pridemore. Stress-Rupture Characterization in Nickel-Based Superalloys Gas Turbine Engine Components. Journal of Failure Analysis and Prevention, pages 281-288, 2008.

19. T. M. Pollock and S. Tin. Nickel-Based Superalloys for Advanced Turbine Engines: Chemistry, Microstructure and Properties. Journal of Propulsion and Power, 22(2):361-374, March 2006.

20. M. Kamaya, A. J. Wilkinson, and J. M. Titchmarsh. Quantification of plastic strain of stainless steel and nickel alloy by electron backscatter diffraction. Acta Materialia, 54:539, 2006.

21. Anish Kumar and Tresa M. Pollock. Mapping of femtosecond laser-induced collateral damage by electron backscatter diffraction. Journal of Applied Physics, 110(8):083114, 2011.

22. Wen J. Tu and Tresa M. Pollock. Deformation and Strain Storage Mechanisms during HighTemperature Compression of a Powder Metallurgy Nickel-Base Superalloy. Metallurgical and Materials Transactions A, 41A, 2010.

23. Phani S. Karamched and Angus J. Wilkinson. High resolution electron back-scatter diffraction analysis of thermally and mechanically induced strains near carbide inclusions in a superalloy. Acta Materialia, 59:263-272, 2010. 